\title{
Learning to Adapt in a Global Pandemic of COVID-19: Insights to Support Vocational Education and Training (VET) in Southern Africa
}

\author{
Emmanuel Ojo, Presha Ramsarup, Nicola Jenkin, School of Education, University of the \\ Witwatersrand
}

\begin{abstract}
The COVID-19 pandemic impacted all education sectors significantly during the full global lockdown between March and June 2020, including the Vocational Education and Training (VET) sector. During this period, the authors jointly led nine researchers who were postgraduate students in six Southern African Development Community (SADC) countries (Botswana, Eswatini, Mozambique, South Africa, Zambia and Zimbabwe). Due to the restrictions during the lockdown, these nine researchers conducted a literature review and thirty interviews in local communities in these six SADC countries. This included both VET colleges as well as individuals in informal, small-scale and entrepreneurial activities. The authors refer to the qualitative data gathered by the interviews with these interviewees as 'stories of adaptation'. In this paper we used these 'stories of adaptation' to explore the links between learning to adapt and expertise, and to consider how together these constructs offer insights into how VET can be strengthened to better support local communities.

Two research questions were asked: (1) how do the notions of adaptive capacity and expertise as conceptual constructs help to understand vocational learning in a global pandemic? and (2) what insights can be drawn from the 'stories of adaptation' to strengthen the role of VET in local communities? Through a thematic analysis of the 'stories of adaptation', three key findings emerged: (1) capacity to adapt is a multi-level and multi-pronged construct; (2) use of digital platforms as well as local networks were key enabling mechanisms for adaptation; and, (3) learning and expertise are embedded in the capacity to adapt. Thus, we argue that building a responsive VET system for the SADC region is achievable by strengthening the nexus between learning, expertise and adaptive capacity.
\end{abstract}

Keywords: adaptive capacity; expertise; global pandemic; vocational education

\section{Introduction}

Vocational Education and Training (VET) has an important role to play in Africa's development (McGrath, 2012; McGrath et al., 2020). VET has a strong relationship to skills for livelihoods. The coronavirus pandemic (COVID-19) is a global shock that has negatively 
impacted on global education, including the VET system. The need for the VET system to adapt through the current global health crisis has become critical (UNESCO-UNEVOC, 2020). This has led to an analysis by the Southern African Development Community (SADC) of the impact of the pandemic on different sectors, including education (SADC, 2020).

The current pandemic is changing the way we live, work and learn and the need for education, including the VET system, to become responsive during such situations is a global imperative. This is the time that we must educate differently for "complexity, change, uncertainty, vulnerability, and resilience" (Talanquer et al., 2020). This paper builds on a recent study (Ramsarup, Ojo \& Jenkin, 2020) which was part of a bigger study called Researchers Challenge in SADC \#OpenupYourThinking. ${ }^{1}$ Our study examined how the Vocational Education and Training (VET) system in the southern African region fared during the lockdown in May and June 2020.

Specifically, this paper acknowledges that VET has an important role to play in supporting livelihoods in local communities. Two research questions are asked as follows: (1) how do the notions of adaptive capacity and expertise as conceptual constructs help to understand vocational learning in a global pandemic? and (2) what insights can be drawn from the 'stories of adaptation' to strengthen the role of VET in local communities? In answering these research questions, the paper explores how what the authors called 'stories of adaptation' contribute to the development of expertise which is central to VET. This helps us to draw out implications for strengthening the role VET plays in local communities.

\section{Context, data and methods}

The COVID-19 pandemic presented an unprecedented situation globally. UNESCO data in June 2020 claimed that over one billion students were physically unable to attend school, training institutions and universities in 144 countries due to the global lockdown (UNESCOUNEVOC, 2020). This context premised the initiative, referenced in the endnote, by JET Education Services and the UNESCO Regional Office for Southern Africa with other partners to engage SADC researchers to study how different groups and institutions responded to the COVID-19 pandemic in the region. Through this initiative, six thematic areas were identified. The authors jointly led one of the themes, Theme 5: Intersecting perspectives on transforming education for sustainable futures: Vocational Education and Training (VET) \& COVID-19 in Southern Africa, during the height of the lockdown.

The research was conducted online as a 'researcher bootcamp'. Theme 5 involved working with nine researchers who represented six countries in the SADC region: Botswana, Eswatini, Mozambique, South Africa, Zambia and Zimbabwe. At the time, the nine researchers were undertaking postgraduate studies across the SADC region in different disciplines. Thirty interviews were conducted between May and June 2020 remotely (through voice and data calls including using WhatsApp voice notes, especially if the network was problematic in the interviewee's location). We referred to the interview accounts as 'stories of adaptation'. These stories illustrated how individuals overcame barriers to maintaining their livelihoods during COVID-19. 
The research adopted a qualitative approach through the use of these 'stories of adaptation', the interviewees' accounts, as qualitative data. In addition to this, a literature review was conducted by the researchers on the overview of VET in their respective countries, with particular reference to policy and the impact of COVID-19. This literature review provided insight into how TVET colleges had responded (or not) during the pandemic. The table below summarises the interviews conducted across a cross-section of individuals involved in informal, small-scale and entrepreneurial activities, and TVET colleges during the COVID-19 lockdown in the six SADC countries.

Table 1: Summary of the 'stories of adaptation' including a cross-section of the activities by number and location

\begin{tabular}{|c|c|c|}
\hline Interviews as 'stories of adaptation' & $\begin{array}{l}\text { Number of individuals } \\
\text { interviewed }\end{array}$ & Location \\
\hline Informal metal manufacturing & 5 & Harare, Zimbabwe \\
\hline \multirow{2}{*}{ Small-scale farming } & 3 & Cape Town, South Africa \\
\hline & 1 & Lusaka, Zambia \\
\hline $\begin{array}{l}\text { Soap manufacture and ingredient } \\
\text { production }\end{array}$ & 4 & Nampula, Mozambique \\
\hline Recycled waste entrepreneurs & 4 & Lusaka, Zambia \\
\hline Tuck-shop ownership & 3 & Francistown, Botswana \\
\hline \multirow{3}{*}{ TVET colleges } & 6 & Manzini, Eswatini \\
\hline & 1 & Nampula, Mozambique \\
\hline & 3 & Durban, South Africa \\
\hline Total number & \multicolumn{2}{|l|}{30} \\
\hline
\end{tabular}

A thematic analysis was carried out on the data collected by the nine researchers and authors of this paper.

\section{Literature}

Vocational Education and Training (VET) "traverses the education-work border" (McGrath, 2011, p. 36), is about intermediate skills necessary to maintain livelihoods in Southern Africa (McGrath, 2005) and is critical to a nation's socio-economic context (Akoojee \& McGrath, 2004). The link between education, work and livelihoods is central to the VET system, and the role of VET in strengthening local communities. We recognise work by Powell and McGrath (2019), which argued that when researchers discuss a specific institutional structure, they utilise the term 'TVET'. However, this paper uses the larger viewpoint on VET as a means of integrating living-working-learning. 
This paper required a lens that enabled us to explore how people adapted during the COVID-19 lockdown. For this, we found the construct of adaptive capacity useful. Adaptive capacity has many different dimensions, but there seems to be consensus on the ability of a system, institutions, groups or actors to cope and adjust to changing circumstances (Phuong et al., 2018). Adaptive capacity can be broadly understood as the ability of people and institutional systems to cope with incremental and rapidly changing conditions (Smit \& Wandel, 2006).

Whether viewed at a collective or individual level, adaptive capacity involves learning. In other words, the 'capacity to learn' is the most important element and always has a positive effect on increasing adaptive capacity (Eakin et al., 2011). Individual perspectives of adaptive capacity focus on individuals' societal knowledge and technical skills (Bos, Brown \& Farrelly, 2013), and their ability to harness and combine system attributes in adaptation processes. An important necessary condition for understanding the collective perspectives of adaptive capacity is the need for enabling social learning (e.g. knowledge co-production, co-management, sharing knowledge and skills, changing attitudes/behaviour) (Bos et al., 2013).

In this paper, we used the construct of expertise to give meaning to the learning journey in the adaptive processes of the local communities. Expertise is used as an overarching term to conceptualise the relationship between work and VET. The concept of expertise embodies both the practical and theoretical components involved in the performance of work of all kinds.

Largely, expertise arises from VET and VET supports the development of expertise. This occurs across a continuum of overlapping processes that feed into each other (Guile \& Unwin, 2019). Guile and Unwin (2019) identified a number of features of expertise found in the literature. In this study the most relevant features of expertise are individual, collective, cross-occupational, socio-material and practice-based. These features of expertise enabled us to examine how expertise is conceived and developed across occupational boundaries and national systems. They bridged a divide between 'explicit' and 'tacit' forms of knowledge. Drawing on the work of Barbour, Sommer, and Gill (2016), Guile and Unwin (2019, p. 31) argued that expertise or the "application of knowing to solve problems" involves a combination of the dimensions. These dimensions are: technical (specific knowledge required to perform); arcane (rules, history - as in a 'community of practice'); interpersonal (relational aspects of practice); and embodied (physical conduct of work and the space in which it takes place).

Traditional conceptions of VET tend to focus on the 'technical', with some attention given to the 'arcane', and separate the 'interpersonal' from practice, as in so-called generic or soft skills. Attention to the 'embodied' aspect of expertise may be given, although not necessarily articulated, and may be encompassed by a more generalised notion that there is a tacit realm to any area of expertise (e.g. trainee carpenters are encouraged to keep running their hands along a piece of wood to test for imperfections, or chefs are encouraged to 'feel' the moment when a sauce starts to thicken) (Guile \& Unwin, 2019, p. 31). Thus, the use of expertise underlabouring adaptive capacities provided us with the descriptive tools 
to articulate the knowledge and practices embedded within the adaptations observed in the study.

\section{Emerging findings}

The analysis of the data is presented in this section as key emerging findings. These emerging findings are clustered as follows: (1) capacity to adapt is a multi-level, multipronged construct; (2) use of digital platforms as an enabling mechanism for adaptation; and (3) learning to adapt and dimensions of expertise are complementary as depicted in the stories of adaptation. These are presented with extracts from the 'stories of adaptation' below.

\section{Capacity to adapt is a multi-level, multi-pronged construct}

This paper required a lens that enabled us to explore how people adapted during the COVID-19 lockdown. For this, we found the construct of 'adaptive capacity' useful. As earlier indicated in the literature, adaptive capacity has many different dimensions and can be broadly understood as the ability of people and institutional systems to cope with incremental and rapidly changing conditions. The first finding depicts three levels of representation for capacity to adapt which includes individual capacity to adapt, adapting to a focus on the local collective/community, and system adaptation as seen in vocational education system support. Each of these levels is discussed in detail below, along with excerpts from the interviews.

\section{a) Individual capacity to adapt}

All researchers reflected on the adaptive capacity of the individuals they interviewed. In the main, they indicated that individual capacity played a significant role in an individual's ability to respond and adapt to the immediate shock of the severe lockdowns across the region. For example, two interviewees, an informal metal worker and a waste recycling entrepreneur, expressed how quickly they were able to reorganise and adopt different mechanisms for the way they sold the products they grew, made or retailed.

"I used to get my scrap metal from broken down machines on farms, but with COVID-19 I acquired non-functional machines locally from peers or material from local scrap yards and suppliers." [Informal metal worker operating in Harare, Zimbabwe]

"We used to have exhibitions to sell most of our products but now we use online channels to sell our baskets and buyers can place orders." [A waste recycling entrepreneur from Lusaka, Zambia]

In the same way, a soap-maker and tuck-shop owner used their own agency and experience to solve problems during the lockdown drawing on their individual capacity to adapt. 
"I saw all the waste coconut, and drew on my chemistry degree to make soap - understanding the setting time, the sequence and time for adding ingredients, and the intensity of the boiling fire." [Soap-maker from Nampula, Mozambique]

"My financial preparedness by saving money, and how to run a business helped me during lockdown." [Tuck-shop owner in Francistown, Botswana]

All those interviewed illustrated their individual ability to draw on their existing knowhow and ability to learn new technical skills. They adjusted their practices to cope with the challenges created by the lockdown. A good example of a combination of these abilities to learn was reflected by a soap-maker.

"I learned from seeing my mother producing coconut oil. When I studied chemistry, I realised that I could do more with coconut. I did my experiments from reading books and watching related videos and it really worked." [Soap-maker from Nampula, Mozambique]

This demonstrates how the individual interviewee's adaptive capability aided in their capacity to learn and adapt.

\section{b) Adapting to a focus on the local collective and community}

Across the different 'stories of adaptation', we were also able to identify a leap from the individual ability to adapt to that of adaptation while leveraging on interpersonal networks and relationships in communities. These networks and relationships supported and enabled local enterprises that developed due to travel and consumer restrictions. As noted by one of the interviewees, "community is critical" [Smallholder farmer in Cape Town, South Africa].

Other interviewees expressed similar understanding of the importance of the community's ability to think and act collectively. Small-scale farmers, tuck-shop owners, metal workers and waste entrepreneurs increasingly relied on localised or walk-in sales, or access to local materials in their communities.

For example, one of the interviewees in Botswana noted their ability to adapt was informed by their local customers who indicated their preferred goods for purchase, such as "small products like soft drinks, toilet paper, face masks and also electricity. Some perishable goods such as vegetables and meat were also in high demand" [Tuck-shop owner in Francistown, Botswana]. This ensured tuck-shop owners sold goods that were most likely to be purchased by local customers during lockdown. This enabled them to continue to generate income during lockdown. Survival capacity was also witnessed in adaptations to procurement practices, which shifted to local suppliers. As illustrated by an interviewee in Zimbabwe, "sometimes I call my friends who own their own [local] companies to assist me ... they will sell me some material" [Metal worker in Harare, Zimbabwe].

Additionally, community knowledge sharing and learning were viewed as crucial for coping, such as connecting with social media or local industry communities. These are expressed in the extract below by the different interviewees. 
"I got in touch with farmers willing to share knowledge and experience ... I saw on various social media how other people and businesses came up with ideas to limit social interaction. I applied these ideas on the farm and with customers. [Through this] food organisations heard about the farm through social media platforms and reached out." [Small-scale farmers in Cape Town, South Africa]

To better illustrate the important significance of the community's collective adaptive capability, two interviewees pointed out the need to learn from one another throughout the lockdown. There was one individual who explained how leaning on personal experience assisted in coping.

"I talked to other tuck-shop owners, and learnt from them." [Tuck-shop owner in Francistown, Botswana]

"I learnt from my parents and guardians." [Small-scale vegetable grower from Cape Town, South Africa]

The importance of capacity to adapt as a distributed competence among communities could thus be traced within the stories and this collective expression of capacity to adapt is essential to understanding VET in local communities.

\section{c) Vocational education system support}

This section draws on data from the literature review of TVET responses to the pandemic in the six countries and the interviewees from TVET colleges in three countries. It was observed that the VET support system struggled to provide consistent educational provisioning during the lockdown's peak and struggled to react at national level within the countries and at college levels. Only South Africa seems to have had the infrastructure necessary to facilitate online education and learning, although this was scattered. The nine researchers involved struggled to obtain national recovery plans, or publicly available information on VET to ascertain national responses to the pandemic. Government attention generally seemed to have been dedicated to the provision of basic and higher education in the region.

Infrastructure and digital capabilities (physical and competence) were two of the most major obstacles experienced at sector level. The primary digital capacity constraints identified were: students lacking access to computers or smartphones (Mozambique, Zambia); the high cost of internet services and data (Zambia); a lack of knowledge regarding the use of technology platforms and smartphones (Zambia); and internet accessibility (especially in rural areas and informal settlements throughout the SADC region). From the institutions' viewpoint, digital limits were infrastructure-related, and the ability to provide courses remotely, particularly technical components, proved troublesome. Financial constraints prevented VET institutions in Eswatini, Mozambique, and South Africa from providing students with computers, cellphones, or data. Capacity for remote delivery of courses was also a challenge, particularly for technical components in South Africa, Mozambique, and 
Zambia. Insufficient teacher capability to exploit digital platforms was identified as an issue for the TVET College in Zambia.

Only two colleges interviewed across the six countries highlighted how they had adapted and used their facilities and practical know-how to capitalise on the sudden demand for masks and sanitisers during lockdown.

\footnotetext{
"The use of skills and entrepreneurial ventures resulted in students and colleges sewing face masks and protective overalls and making sanitisers. This turned into small businesses and provided the student and TVET institutions with practical experience." [Senior education specialist at a TVET college in Durban, South Africa]

"We've got lots of practical rooms which we can use for example jewellery design. The room was locked for four years. Now the students are making masks in these rooms. We can be proud about this. Students are learning how to come up with their own designs." [Head of Programmes at a TVET college in Durban, South Africa]
}

The three levels of representation for adaptability as presented above, which include individual adaptability, adaptability with an emphasis on the local collective/community, and vocational education system jointly support adaptive capacity as a multi-level, multipronged construct. The levels are also iterative and interconnected.

\section{Use of local networks and digital platforms as enabling mechanisms for adaptation}

According to the interviews, there was an exponential growth in the usage of digital platforms during the lockdown. Smartphones were mostly utilised to communicate, obtain knowledge, purchase supplies, and sell things, as evidenced by the various statements of the interviewees.

"I used WhatsApp to communicate quickly with other farmers to deal with urgent issues when social distancing and travel restrictions stopped me from meeting them." [Small-scale farmer, Lusaka, Zambia]

"I used social media more to share information with farmers." [Small-scale farmer, Cape Town, South Africa]

"I learnt to use social media to collect the coconut waste by calling the coconut seller. I also used an electronic transaction to engage with the carrier." [Soap-maker, Nampula, Mozambique]

"I learnt how to use social media as a tool for advertising my goods." [Waste recycling entrepreneur, Lusaka, Zambia]

The findings emphasise the critical need of having access to local networks within communities and being able to employ digital tools (online media platforms and applications) in order to cope with a crisis of this magnitude, such as the COVID-19 pandemic. There is evidence, as presented in the extracts earlier, that a number of the interviewees have online presence through the use of social media platforms such as WhatsApp. Some of them used 
this to continue to sell their goods or crops. In addition to this, they relied on their local networks during the lockdown to cope. To put it another way, when social separation and travel constraints prevented individuals from meeting in person, they drew on the networks within their communities and on smartphone apps like WhatsApp to enable them to adapt.

\section{Learning to adapt and dimensions of expertise are complementary as depicted in the stories of adaptation}

From the 'stories of adaptation', we were able to extract work tasks, skills and knowledge as depicted in Figure 1 below. These helped to illustrate and understand the learning processes central to the 'development of knowing to solve problems,' which is the essence of expertise (Guile \& Unwin, 2019). The different 'stories of adaptation' focused on individuals having a particular trade or job, such as soap-makers, small-scale farmers, tuck-shop owners or metal workers, and the technical tasks they presented related directly to the specifics or technical dimensions of their job. For example, for the soap-maker such tasks included the making of soap from coconut waste. In the interview account of the waste recycling entrepreneur producing bags from plastic waste, one of their tasks included the knitting of plastic. For the tuck-shop owner, this included the buying and selling of goods.

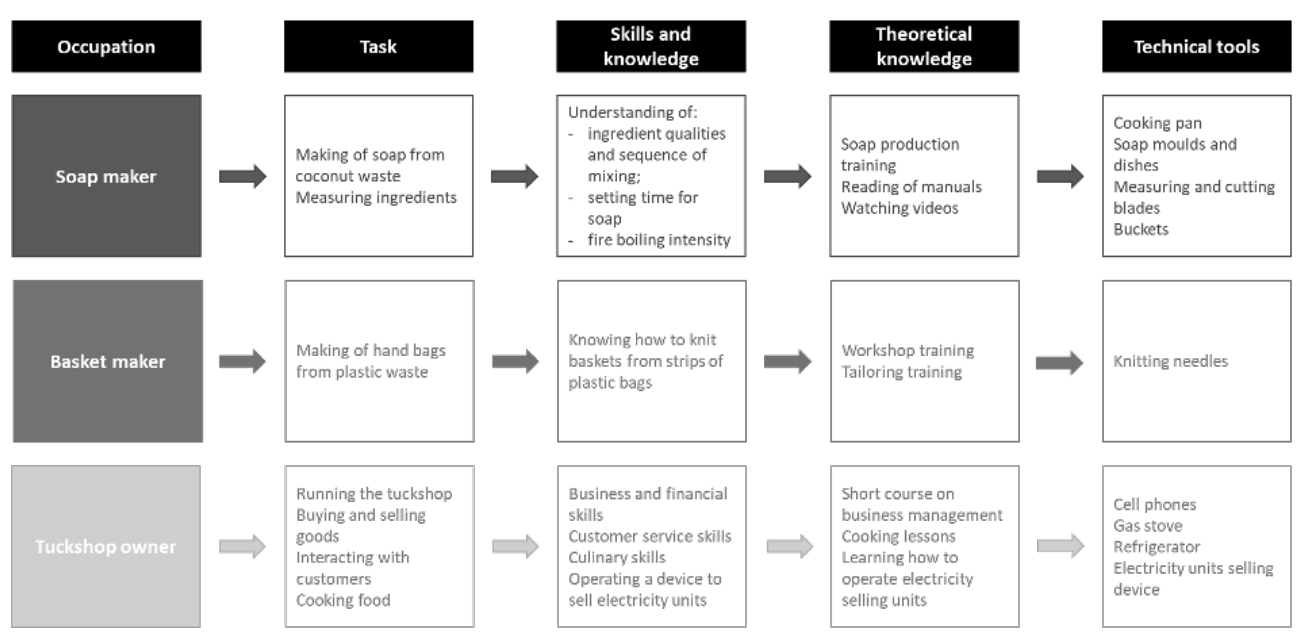

Figure 1: Illustration of 'stories of adaptation' where the relationship between tasks, skills and knowledge is shown (Ramsarup, Ojo \& Jenkin, 2020, p. 32)

However, many of the individuals interviewed also mentioned tasks that could be considered non-specific, and, therefore, generic - making them applicable to more than one task or job. Examples include business and entrepreneurial, research, and customer services skills. These tasks are associated with knowledge skills which will have been obtained more informally or tacitly (for example, on the job learning and through the use of certain tools). 
Further analysis helped to show the combination of dimensions of expertise embedded in the interviews to adapt, and showed the technical dimension i.e. the specific knowledge required to perform work tasks. In the soap manufacturing interview, for example, there was an emphasis on the need to understand ingredient properties, the sequences necessary to combine them, and knowing when to add the ingredients. Additionally, the degree of intensity of the boiling fire and the soap setting time are all critical. In the case of the waste recycling entrepreneurs, the basket maker needed to know how to combine wires with bottle tops to make a functional shopping basket, and the floor polish maker needed to know the quantity of paraffin and colour to add to the melted mixture of plastics (Ramsarup, Ojo \& Jenkin, 2020).

The arcane dimension as the rules of practice was evident in the small-scale farmer from Lusaka, Zambia. As an example, drawing on the interview, knowing and understanding disease regulations, animal vaccines or fertiliser requirements are all important. Evidence of new rules of practice adoption were also witnessed, from adopting sanitisation and social distancing protocols, and travel restrictions.

"Levels of hygiene had improved through heightened adoption of sanitations protocols."

[Waste recycling entrepreneur from Lusaka, Zambia]

"During the first days of the lockdown I had to acquire a permit to travel to the wholesale market." [Smallholder farmer in Cape Town, South Africa]

Interpersonal dimensions involve the relational aspects of practice and were observed in the interviews. An example is: "I acquired the knowledge through a product recycling association" [Waste recycling entrepreneur from Lusaka, Zambia]. For smallholder farmers, these dimensions included engaging with participants in food relief programmes, community leaders and social media/news. This relational dimension emerged as central to how information was acquired during the height of the lockdown.

Linked to the interpersonal dimension is the access to local knowledge, in terms of geographic location. This proved a significant indicator for knowledge access during the COVID-19 restrictions. Given the travel restrictions imposed on local businesses during periods of lockdown, local community knowledge - like speaking to those within the same job role or operating in the same sector (e.g. farming) - appears to have been a valued and important source of knowledge generation and acquisition.

The embodied dimension - the physical conduct of work and the space in which it takes place - was more difficult to ascertain. This was due to the researchers not being allowed to conduct site visits, and therefore observe the physical conduct of work. As such, it was not reported.

The data thus illustrates that through examining capacity to adapt, we were able to surface dimensions of expertise, thus enabling us to link development of expertise and capacity to adapt.

Table 2 that follows summarises the three key findings that emerged from the data analysed for this paper. 
Table 2: Summary of the emerging findings from the data

\begin{tabular}{|l|l|}
\hline Emerging findings & Summary \\
\hline $\begin{array}{l}\text { Capacity to adapt is a multi-level, multi- } \\
\text { pronged construct }\end{array}$ & $\begin{array}{l}\text { Adaptability may be defined as consisting of three levels: } \\
\text { individual adaptation, adaptability for the local community, } \\
\text { and support for the vocational education system. These } \\
\text { levels are also iterative and interrelated. }\end{array}$ \\
\hline $\begin{array}{l}\text { Use of local networks and digital platforms } \\
\text { as enabling mechanisms for adaptation }\end{array}$ & $\begin{array}{l}\text { An online presence and local networks were vital for the } \\
\text { interviewees to develop the capacity to adapt. Digital } \\
\text { platforms like WhatsApp proved useful for facilitating } \\
\text { communication regardless of geographic or social isolation. }\end{array}$ \\
\hline $\begin{array}{l}\text { Learning to adapt and dimensions of } \\
\text { expertise are complementary as depicted } \\
\text { in the stories of adaptation }\end{array}$ & $\begin{array}{l}\text { The relationship between tasks, skills and knowledge, } \\
\text { theoretical knowledge and technical tools are embedded } \\
\text { in the 'stories of adaptation' showing strong links with } \\
\text { expertise. This has significance for VET where expertise } \\
\text { development is central to the role of VET. }\end{array}$ \\
\hline
\end{tabular}

The next section discusses these results, linking the research questions and the literature earlier presented in this paper.

\section{Discussion}

Drawing on the conceptual construct of adaptive capacity, and Guile and Unwin's (2019) dimensions of expertise, it was possible to explore the interplay between the individual, the collective community and the VET college's adaptive capacity during the severe restrictions imposed at the onset of COVID-19 pandemic. This discussion highlights how the interviewees developed the capacity to learn to live with uncertainty and change, while specifically highlighting adaptive capacity through the lens of knowledge, learning and expertise.

The data illustrated that the capacity to adapt was multi-level and multi-pronged. The three levels identified were adaptability at the individual, the local community and at the VET system level. What was common in the varied ways in which adaptive capacity emerged was the strong sense of adaptation as the use of knowledge to solve issues which Guile and Unwin (2019) embedded as core to expertise. Such competencies identified from the 'stories of adaptation' include, for example, the ability to focus and solve problems to sustain an income when COVID-19 restrictions limited access to market. The types of activities implemented by those interviewed to illustrate such fortitude and ability to adapt included: the identification of different means for marketing their products, such as the use of social media; the hiring of a driver to deliver products when previous modes of logistics and delivery were restricted; and the purchase of Personal Protective Equipment (PPE) to comply with safety measures to continue trading. For those selling a craft, some showed use of local networks and many highlighted that online access proved critical for survival; for those that did not have the means to access the internet or social media to sell their goods, this proved to be a barrier to continue to do business. 
This ability to apply knowledge to solve problems, according to Guile and Unwin (2019), involves a combination of dimensions of expertise - technical, arcane, interpersonal and embodied. Guile and Unwin (2019) suggested these dimensions of expertise will comprise tasks associated with knowledge and skills, which will have been obtained more formally, or tacitly e.g. on-the-job, and through the use of certain tools. We argue that while expertise is central to VET, adaptation cannot happen without learning. As individuals, communities or systems adapt, new learning is taking place. Therefore, acknowledging the role learning plays in adapting and building expertise is important for a better VET system.

The type of learning underpinning the development of expertise that surfaced was dynamic and contingent where meaning and status are constantly in flux as was necessary in the pandemic; these fixed and rigid ideas about theory and practice should hence be guarded against. It also looks at the development of expertise across a "continuum of overlapping processes that feed into each other: the initial process of formation, the refreshing and updating process, and the reformulation process' (Guile and Unwin, 2019, p. 33). Perceiving learning and expertise processes as a continuum as depicted in the stories is a way to discourage narrow tasks, and competence-based notions of vocational learning that characterises most VET systems.

The real-life experiences evident in the stories show that while learning to adapt is happening at different levels, the learning focus is largely cross-occupational. Different occupations were represented in the stories and the need to link theory to practice is imperative. The analysis of the 'stories of adaptation' further helps us to see expertise as relational and distributed which mitigates the dualistic framings common in VET like formal and informal learning, practice and theory, knowledge and skill, institution and community. As such, VET must pay attention to how these are framed within the dominant learning processes.

Learning and expertise within VET is critical to strengthening VET. This is supported by Guile and Unwin (2019). The authors argued that "each process needs to be underpinned by a concept of expertise that enables an individual to understand that: (a) they are engaged in a multi-faceted process of learning that will draw on different sources and types of knowledge (including their own), and (b) their expertise will be formed through practice and in relation to other people and different technologies and be subject to shifting formulations and value judgments" (Guile \& Unwin, 2019, p. 33). If VET systems can support the development of this kind of learning, which is central to expertise, this will strengthen the VET system and ultimately enable VET to play a more meaningful role in supporting local communities.

The stories of adaptation also presented the importance of digital platforms as the operational space to bring together the nexus between learning and expertise. We acknowledge the role of access to digital platforms as combining features of 'crossoccupational and socio-material' elements (Guile \& Unwin, 2019, pp. 29-30). Within these stories there is overwhelming evidence of the use and importance of digital platforms, including how the original research was conducted using digital platforms such as Google Drive and WhatsApp for communication, and through the stories on how individuals used such platforms for work and trade. Examples of the latter included making payments, 
selling goods, accessing suppliers of raw materials, connecting and sharing knowledge. The World Bank alluded to the use of digital platforms and technologies during the first phase of the pandemic in aiding businesses to stay open, thereby making society more resilient (Lampietti, Abed \& Schroeder, 2020). Digital tools can also be considered as boundary crossing tools that enable the opportunities to facilitate learning and the ability to better adapt for the multi-level, multi-pronged nature of capacity to adapt presented previously.

It was also evident that non-formal VET grew during this time, with numerous local initiatives emerging alongside efforts to support local economies (Ramsarup, Ojo \& Jenkin, 2020). This need prompted the agentic desire displayed in lead agents in stories for new knowledge and skills. This precipitated the need for relevant occupational programmes and curriculum reinvention. For example, a number of calls were made by those interviewed for vocational courses which focused on providing practical knowledge and skills, such as sewing, cooking, gardening, farming (e.g. how to plant crops and maintain soil fertility) and operation of advanced or computerised machines. Such practical skills and knowledge would enhance current practices (e.g. diversifying products, ensure skills are up to date or to improve the success of crop production and yields). Technical skills are specific to the occupation and, if made available, are likely to improve the sustainability of livelihoods, especially during a shock to the system.

However, upon investigation, the mechanisms that emerged during the severe lockdown by VET institutions to support and sustain livelihood enterprises are unclear. While respondents could articulate types of knowledge and skills they would like to use in future to strengthen enterprises, they were unclear about where and how they could receive such capacity development within their local communities. In addition, they often struggled to articulate what such a potential pathway may be - particularly the metal workers in Harare. Thus, links between these emergent enterprise opportunities and an emergent VET pathway appear unclear because signposting of learning pathways in the vocational context seemed unclear to interviewees.

During the time of the initial wave of the pandemic, there appeared to be several calls for VET to 'reinvent' itself. However, clear guidelines and national interventions are not yet visible as much of the discourse is rhetorical and without a substantiated pathway to action. Such a pathway, or reinvention, could potentially use this COVID-19 shock to the system to:

- Reform the curriculum (see recommendations below);

- Increase VET focus on occupational programmes relevant to communities as relevant to research, curriculum and teaching and learning;

- Build and enhance partnerships with local communities, industry and local government;

- Become responsive to skills needed to cross boundaries e.g. digitalisation;

- Build more clear entry level pathways that connect to livelihoods. 
If we strengthen the VET system, the resultant impact will enhance and strengthen the livelihoods of individuals and local communities. We argue that building back a better VET system is possible through this type of responsiveness.

During the initial hard lockdown, the refocus on the local (particularly local products, economies and waste) as a resource illustrated the re-emergence of local sources and resources in the communities studied. Links between VET institutions and livelihoods in communities therefore need to be explored further as they hold important lessons for supporting adaptive capacity in communities and understanding how to better connect livelihood opportunities into the formal VET system.

\section{Conclusion}

In this paper, we have argued that the interplay between adaptive capacity, learning and expertise that surfaced from 'stories of adaptation' collected during the pandemic provided an understanding of the VET system in local communities. The paper provided critical insights to building a more responsive and adaptive VET system, and to better understand how to build back better through and after the global shock so that VET can play a stronger role in local communities.

\section{Acknowledgements}

The authors would like to thank the study team that worked on the original report for this paper. This involved nine scholars from six of the SADC region member countries: Lebogang Basimane (Botswana), Vincent Madhlopa (eSwatini), Deocleciano Nhazilo and Orquidia Chilundzo (Mozambique), Katlego Leshabane and Tayyibah Tahier (South Africa), Lazarus Mfula (Zambia), and Tarisai Manyati and Mayibongwe Shongwe (Zimbabwe). We thank Umar Kyari (Nigeria), JET Research Assistant and the peer reviewers: Stefan Thomas (ETF), Khaya Tyatya, Volker Wedekind and Robin Sanasee for their contributions.

\section{Notes on Contributors and their Contributions}

\section{Lead author}

Ojo, Emmanuel

Dr Emmanuel Ojo is Senior Lecturer at the School of Education, University of the Witwatersrand. His research work focuses on higher education, sustainability and interdisciplinary research. 


\section{Co-author}

Ramsarup, Presha

Dr Presha Ramsarup is Director at the Centre for Researching Education and Labour at the University of Witwatersrand. Her research work focuses on green skill learning pathways for sustainable development.

\section{Co-author}

\section{Jenkin, Nicola}

Dr Nicola Jenkin is a researcher with Centre for Researching Education and Labour at the University of Witwatersrand. She has extensive experience in the field of sustainability including sustainable food systems and green skills.

\section{Percentage contribution}

\begin{tabular}{|c|c|c|}
\hline Areas of contribution & Author & $\begin{array}{l}\text { Percentage } \\
\text { contribution }\end{array}$ \\
\hline \multirow{3}{*}{ Conception or design of the paper, theory or key argument } & Ojo & $40 \%$ \\
\hline & Ramsarup & $40 \%$ \\
\hline & Jenkin & $20 \%$ \\
\hline \multirow{3}{*}{ Data collection } & Ojo & $35 \%$ \\
\hline & Ramsarup & $35 \%$ \\
\hline & Jenkin & $30 \%$ \\
\hline \multirow{3}{*}{ Analysis and interpretation } & Ojo & $40 \%$ \\
\hline & Ramsarup & $40 \%$ \\
\hline & Jenkin & $20 \%$ \\
\hline \multirow{3}{*}{ Drafting the paper } & Ojo & $45 \%$ \\
\hline & Ramsarup & $45 \%$ \\
\hline & Jenkin & $10 \%$ \\
\hline \multirow{3}{*}{ Critical review of paper } & Ojo & $45 \%$ \\
\hline & Ramsarup & $45 \%$ \\
\hline & Jenkin & $10 \%$ \\
\hline
\end{tabular}




\section{References}

Akoojee, S. \& McGrath, S. (2004). Assessing the impact of globalization on South African education and training: A review of the evidence so far. Globalisation, Societies and Education, 2(1), 1-39.

Barbour, J.B., Sommer, P.A. \& Gill, R. (2016). Technical, arcane, interpersonal and embodied expertise Expertise, communication, and organizing. Oxford, UK: Oxford University Press. pp. 10-12.

Bos, J.J., Brown, R.R. \& Farrelly, M.A. (2013). A design framework for creating social learning situations. Global Environmental Change, 23(2), 398-412.

Eakin, H., Eriksen, S., Eikeland, P.-O. \& Øyen, C. (2011). Public sector reform and governance for adaptation: Implications of new public management for adaptive capacity in Mexico and Norway. Environmental Management, 47(3), 338-351.

Guile, D. \& Unwin, L. (2019). VET, Expertise, and Work: Situating the Challenge for the Twenty-First Century. In D. Guile \& L. Unwin (Eds.), The Wiley Handbook of Vocational Education and Training. Hoboken, NJ: Wiley Blackwell. pp. 19-40.

Lampietti, J., Abed, G.E. \& Schroeder, K. (2020). Beyond the pandemic: Harnessing the digital revolution to set food systems on a better course. Retrieved from https:// www.worldbank.org/en/news/immersive-story/2020/08/06/beyond-the-pandemicharnessing-the-digital-revolution-to-set-food-systems-on-a-better-course

McGrath, S. (2005). The multiple contexts of vocational education and training in southern Africa. In S. Akoojee, A. Gewer \& S. McGrath (Eds.) Vocational education and training in southern Africa: A comparative study. Cape Town: HSRC Press. pp. 1-8.

McGrath, S. (2011). Where to now for vocational education and training in Africa? International Journal of Training Research, 9(1-2), 35-48.

McGrath, S. (2012). Vocational education and training for development: A policy in need of a theory? International Journal of Educational Development, 32(5), 623-631.

McGrath, S., Ramsarup, P., Zeelen, J., Wedekind, V., Allais, S., Lotz-Sisitka, H., Monk, D., Openjuru, G. \& Russon, J.A. (2020). Vocational education and training for African development: A literature review. Journal of Vocational Education \& Training, 72(4), 465-487.

Phuong, L.T. H., Wals, A., Sen, L.T.H., Hoa, N.Q., Van Lu, P. \& Biesbroek, R. (2018). Using a social learning configuration to increase Vietnamese smallholder farmers' adaptive capacity to respond to climate change. Local Environment, 23(8), 879-897.

Powell, L. \& McGrath, S. (2019). Skills for Human Development: Transforming vocational education and training. Milton Park, Oxon: Routledge.

Ramsarup, P., Ojo, E. \& Jenkin, N. (2020). Intersecting perspectives on transforming education for sustainable futures: Vocational Education \& Training (VET) \& COVID-19 in Southern Africa. Retrieved from https://www.jet.org.za/resources/sadc-researcherschallenge-theme-5-vocational-education-training-covid-19-in-southern-africa.pdf/ download 
SADC (Southern African Development Community). (2020). SADC Regional Response to COVID-19 Pandemic: An Analysis of the Regional Situation and Impact. Retrieved from https://www.sadc.int/files/6815/8758/9636/BULLETIN_2-SADC_Response_to COVID19_ENGLISH.pdf

Smit, B. \& Wandel, J. (2006). Adaptation, adaptive capacity and vulnerability. Global Environmental Change, 16(3), 282-292.

Talanquer, V., Bucat, R., Tasker, R. \& Mahaffy, P.G. (2020). Lessons from a Pandemic: Educating for complexity, change, uncertainty, vulnerability, and resilience. Journal of Chemical Education, 97(9), 2696-2700.

UNESCO-UNEVOC. (2020). TVET peer support in response to COVID-19. Retrieved from https://unevoc.unesco.org/home/COVID-19+disruptions

\section{Endnotes}

1 Researchers Challenge in SADC \#OpenupYourThinking

https://www.jet.org.za/news/join-the-researchers-challenge-in-sadc-openupyourthinking 